\title{
Tree risk assessment: a review of methods
}

\section{Peter Sterken}

A reliable and accurate method for tree risk assessment has been the holy grail of arboriculture for decades. With so much at stake if we get it wrong, arboriculturists must continue to question and re-evaluate the methods available to us.

A combined visual method for tree assessment Hypothesis versus reality was published in Sterken 2006: the V method calculates the critical wind speed at which a tree will hypothetically break. The SIA (Statics Integrated Assessment) method (Wessolly and Erb, 1998) calculates the hypothetical breaking-point and safety factor of a tree when the tree is acted upon by wind of a certain speed. In SIM (Statics Integrated Methods) pulling tests (Wessolly and Erb, 1998), trees are statically loaded to calculate their hypothetical safety factor (the point at which they will break or uproot). In the wake of these methods, other similar approaches have also been developed. This article offers an update on the limits of these tree-assessment methods, because trusting them blindly could lead to unexpected tree failure.
Firstly, there is currently no definitive method for predicting the failure of an individual tree (James et al., 2014). Hence, no method can claim to guarantee against tree breakage, uprooting or crown failure. This is a fact that has to be weighed against the often high cost of instrumental tree assessment methods.
Secondly, no scientific evidence has been found to date which shows that the results of these methods are borne out by the effects of real winds on real trees. Sterken 2006: 'It is acknowledged that there is no statistical evidence yet to show a comparison between predicted results from the model against real outcomes.'

Also, trees can break or uproot at lower wind speeds than the forces predicted by pulling tests as necessary for failure to happen: a tree can fail unexpectedly after having been assessed as 'safe'. Very significant findings in this regard were published as long ago as 1992 by Baker and Bell (1992) and were replicated by James (2010). Also, Peltola (2006) suggests

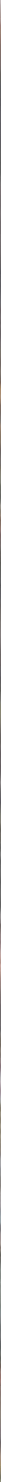


that the processes behind wind-induced damage to trees are not fully understood yet, and thus these methods can only claim to give an indication of the likelihood of failure. The assessment of the mechanical stability of trees by simulating static loading (pulling test) is not sufficient on its own, and the calculation of the wind load in the crown is problematic when the real streamlining properties of the tree are unknown (Peltola et al., 2006). The splitting of buttresses due to the force of the wind or while performing a pulling test (Claire et al., 2003) should also be taken into account, as many trees may fail in this way.

So, common structural failures and complex loading combinations cannot always be predicted by the V, SIA, SIM and similar methods (Sterken, 2006 and Sterken, 2005). However, Wessolly and Erb (2016, page 233) see the failure of hollow tree structures as behaving like the buckling of a hollow grass stalk. And by assuming this they 'self-validate' the informative value of their pulling test method. This should raise serious doubts in anyone who is familiar with the complex ways hollow tree structures can break. Moreover, grass is not wood. But - and above all - Wessolly and Erb also say that 'In areas where structural failure occurs earlier, it should be checked once more whether the tree cavity really maintains its regular shape over a greater length [sic.].' The fact is, many damaged trees do not have cavities with a regular shape. Does this mean that the reasoning set out in Wessolly and Erb 2016 cannot be used on trees with irregular cavities? Leaving out trees with irregular cavities would be a serious limitation on the efficacy and usefulness of a tree assessment method.

Trees, structurally complex as they are (especially the apparently structurally very weak ones which are the typical candidates for a pulling test, the SIA and other similar methods), cannot be seen as a perfect beam. The assessment methods described in this article assume that the tree is a perfect pole or hollow tube made out of an isotropic material (the same material properties in all anatomic directions), and the wind speed under which it will fracture is to be calculated with the theory of the elastic limit of the fibres under axial compression. This should induce the reader to ask the following questions (also bearing in mind Wessolly and Erb's reasoning [2016, page 233], discussed above): 'The trees that I pretend to assess by means of these methods, are they really perfectly shaped poles or tubes? Or are there any eccentric or open cavities, cracks, irregular geometries, bent trunks, and so on?' The answer to the first question will probably be a resounding 'No' and a 'Yes' to the second, because if the trees were not so severely damaged structurally, the use of these methods would not have been considered. Thus, should we ask ourselves whether these methods should be used at all?

Care should also be taken for a further reason: the foundations of the methods as proposed by Wessolly and Erb (2016), i.e. aerodynamic drag factors, wood properties (Stuttgarter Strength Catalogue) and the generalised tipping curve, should rely on supporting

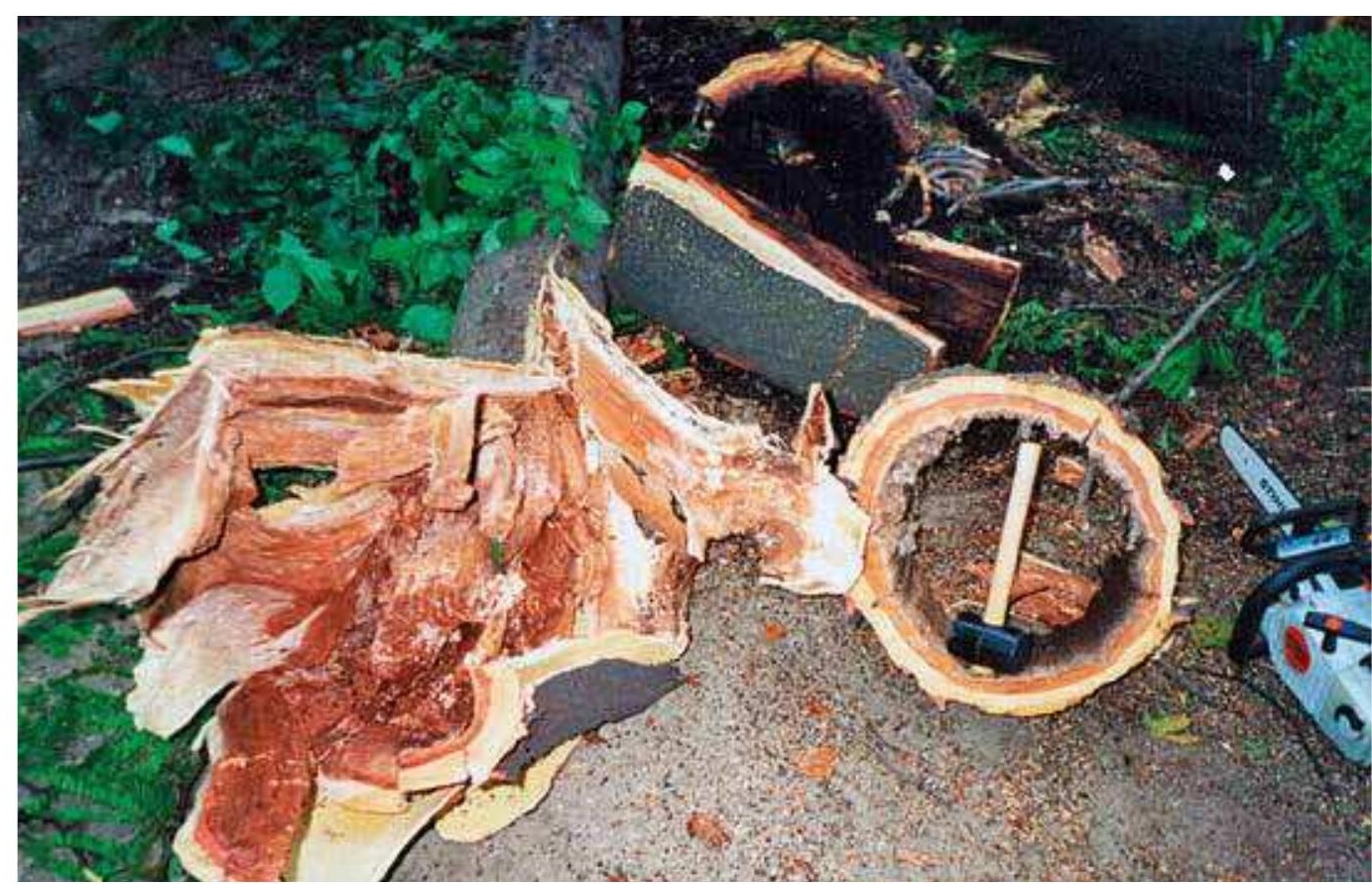

Failure of a hollow Gleditsia triacanthos. Note the two wedges pointing outwards, although the residual wall looks perfectly concentric and closed. Mechanical defects such as these may lead to catastrophic failure but are not predictable with current methods.

and scientifically sound data. However, we have not found any clear references pointing towards scientific, peer-reviewed papers in Wessolly and Erb 2016 relating to scientifically sound data and scientifically contrasted procedures. Hence, we still have to guess whether the drag factors, the wood properties and the tipping curve are hypothetical or not. The wood properties as published by Niklas and Spatz (2010) could replace the Stuttgarter Strength Catalogue (Wessolly and Erb, 1998) as the former are not only more complete but have also been published in a scientific, peer-reviewed journal.

Additionally, curved trunks, stems and branches can split before longitudinal compression yield of the wood occurs (Ennos and van Casteren, 2009). This means that all three methods compared here (even the elastometer pulling test) are useless in predicting this very common failure because they are based solely on the longitudinal compression failure of the wood (Wessolly and Erb, 2016).

The methods compared here use only one fixed value for the modulus of elasticity and density respectively per tree species. For the latter finding, Spatz and Pfisterer (2013) rightly suggest a safety factor of $200 \%$ instead of the $150 \%$ as used by the pulling tests (SIM). They also agree with Sterken 2006 that 'Real trees and real winds usually do not fit themselves to the mathematics' and that trees are dynamic structures.

It should be said that it is not my intention to invalidate the methods evaluated here, but to point out that tree safety assessment methods are still in their infancy. The correct interpretation of their results could save lives, and that is the reason why these guidelines have been given. I also acknowledge that the V-model (Sterken, 2006) suffers from the same limitations.

\section{On residual walls}

Mattheck et al. (2008) criticised the SIA and pulling tests (SIM) and Wessolly's 'stormsafe' cross-sections, but they overlooked a crucial finding that would have supported their criticisms: in Detter et al. (2005) it is quoted that: 'They [the pulling tests with the ElastoInclino Method] also allow for determining the thickness of residual walls without the use of invasive instruments' and a figure is produced where, supposedly, the residual wall thicknesses of 4,807 trees are represented, suggesting that many trees only need extremely small t/R ratios. The same figure was later reproduced by Bond (2006). Wessolly and Erb (1998) reproduce an earlier diagram.

However, extreme care should be taken when interpreting these results as they may be very misleading. The degree of hollowness as published by Detter et al. (2005) is based on four assumptions:

a) a hypothetical modulus of elasticity taken from the Stuttgarter Strength Catalogue (Wessolly and Erb, 1998);

b) calculating the cross-section of the measured tree with the help of calipers, assuming an ellipse cross-section instead of the real cross-section;

c) measuring fibre elongation with elastometers while applying a static load to the tree; and

d) simple engineering equations from common textbooks.

The following discussion is offered to examine the issue of calculating residual wall thickness in greater detail.

Firstly, within species, material properties, such as the modulus of elasticity, can differ 
in the same cross-section of the same tree between parts of the same tree or from tree to tree, and might easily deviate from the value published in strength tables such as those used in the pulling tests.

Secondly, many trees have an irregular stem base and root flares that, seen as a cross-section, do not resemble an ellipse. The elastomethod uses calipers to measure the biggest diameters of the stem (base) at the height of the elastometer measurement (usually at the point where a structural defect, e.g. a cavity, is suspected to be) and its subsequent calculations assume the tree to be an ellipse. Thus, the calculations can assume a much bigger cross-section modulus than the real one with the tree's root buttresses and the spaces between them. Overestimating the load-bearing geometry leads to a distorted vision of the assessed area's stiffness and resistance to bending.

Thirdly, the extent of the elongation of the fibres while the tree is being pulled is measured with elastometers (strain gauges). If the elastometers are not placed properly, e.g. on curved areas or on curved root flares, the readings can be higher than the real microscopic deformations, which results in misleading measurements.

\section{And finally, simple engineering formulae} from common textbooks are applied where the often overestimated cross-section modulus is combined with the hypothetical modulus of elasticity (which can easily be much higher than the real material property in the tree) and the strain measured during the static pulling (where readings can be higher than the real deformations).

The result is that the calculations can indicate a much lower hypothetical stiffness than that assumed by the pulling tests. The 'residual wall thickness' is then calculated simply on the basis of the pulling test by means of simple engineering formulae. And, as all the assumptions can be questioned from the start (except for the measured fibre elongation, and this only if the elastometers were placed properly so as to avoid incorrect readings), the results can be questioned too, and therefore the calculations and the 'degree of hollowness' as published by Detter et al. (2005), Bond and Wessolly and Erb should be approached with care.

The residual wall thicknesses as published in Detter et al. (2005) are not real values but hypothetical ones, and interpreting those results as 'real residual wall thicknesses found' is a dangerous mistake. It is ambitious to claim that '2,171 standing trees have a t/R between 0.0 and $0.3^{\prime}$ as we have not found any clear references pointing towards scientific, peer-reviewed papers in Wessolly and Erb (2016) regarding scientifically sound data and scientifically contrasted procedures which could support this statement. If the pulled trees had been cut afterwards in order to measure their actual $t / R$ (if there really was a closed and concentric residual wall) and this measurement had been compared to their hypothetical $t / R$, there would have been hard evidence to support this ambitious statement. No clear references have been found in their bibliography (Wessolly and Erb, 2016) that would point towards scientific publications of their own showing the procedures and formulae employed. Hence, it is impossible to test the validity of the latter.

In Wessolly and Erb 2016 the same diagram is reproduced again, this time with the pulling test results of 8,140 trees. The diagram strongly suggests that 3,729 standing trees have a t/ $\mathrm{R}$ ratio between 0.3 and 0.0 . And even though this time the authors recognise that the diagram is a result of mathematically converted elastometer readings, theirs is neither a transparent explanation nor provides the necessary warning. Consequently, it is advised here that Wessolly and Erb (and the other authors who have published this idea) reformulate both their statements and the diagram as both could lead to serious misinterpretations. Non-experts could easily, and erroneously, conclude that trees can be safe with $\mathrm{t} / \mathrm{R}$ ratios as low as nearly 0.0 .

On the other hand, in 2008 Gruber had already suggested that the VTA-t/R=0.32 rule and the famous diagram as published by Mattheck were flawed, which means that both Mattheck's diagram and Wessolly and Erb's diagram, both of which have been the basis for tree assessment ever since, should be doubted from a scientific perspective.

\section{The t/R discussion}

Bitter arguments about the $t / R$ which a tree needs to be safe have pervaded arboriculture since the 1990s. The discussion always concerns how hollow a tree may be, and remain safe, if the residual wall is completely concentric and closed. But how many hollow trees are actually like this engineer's idealised dream that sees the tree as a hollow pipe made of isotropic material? Exactly: very, very few. Most cavities are eccentric, irregular, open or even combined with other structural weak spots such as more openings, cracks, included bark, branch attachments, and so on. This, evidently, renders the historic $\mathrm{t} / \mathrm{R}$ discussion ridiculous.

\section{Method}

Huang et al. (2017) suggest critical values for $\mathrm{t} / \mathrm{R}$ with regard to Brazier buckling, cross-sectional flattening and the failure of a hollow stem under pure bending-induced compression stresses. They show that the failure modes and the corresponding $t / R$ ratios are: Brazier buckling $(0<t / R<0.06)$; tangential cracking followed by longitudinal splitting $(0.06<\mathrm{t} / \mathrm{R}<0.27)$; and conventional bending failure $(0.27<t / R<1)$. These results could be extremely valuable guidelines for assessing hollow trees. The calculations of the methods described above would then only be feasible and credible when the $t / R$ found is bigger or equal to t/R 0.27. A t/R of less than 0.27 would induce structural failure of the hollow stem but this is not what the methods above predict, which gives more credibility to Mattheck's famous 0.32 value (which, according to
Gruber (2008), he actually adopted from an earlier author called Wagener (1963)).

Based on this discussion, the following protocol could be proposed, which could serve as a way forward until a reliable method for the safety assessment of trees is found. If the tree trunk has a perfectly closed and concentric residual wall lacking any structural flaws (which, admittedly, is not very often the case), it would not be unreasonable to assume that the following could be good criteria for judging a tree's risk of failure:

A minimum $t / R$ of 0.27 so as to prevent the previously discussed types of structural failure.

This residual wall should have a safety factor in relation to wind loads of $200 \%$ minimum. This factor can be calculated with equation 7 from Sterken 2006

If the residual wall has a t/ $\mathrm{R}$ ratio less than 0.27 , the tree enters into the realm of unpredictable structural failures. Naturally, both the limits of this protocol and the complex combination of forces, material and structure should be taken into account. This, however, can only be done visually, as no current instrumental method or software is able to perform this task. Also, proper training in our method is crucial.

Future research on structurally damaged palms and trees could include placing strain gauge sensors in such a way as to measure the microscopic deformations in all anatomical directions, while subjecting the palm or tree to loads. The combination of stresses (e.g. tangential, shear and torsion) with the very low strength of wood in terms of splitting may trigger the collapse of the tree, and not just because of high longitudinal (parallel to the grain) stresses (Sterken, 2005 p. 42 and Clair et al., 2003).

Cabling and pruning can be considered in order to avoid the collapse of the remaining shell because of weakly attached stems and branches. And even though some who favour commercial synthetic cabling systems (such as Wessolly and Erb, 2016) claim that these would help the tree to compensate for defects, by allowing slight and damped movements thanks to shockdampers, this has not been demonstrated yet in scientific, peer-reviewed literature. As a result, their claim remains a hypothesis.

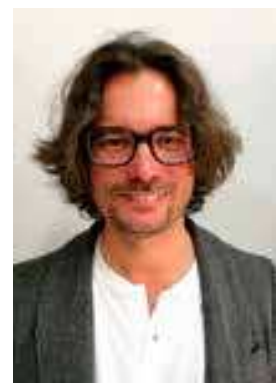

Peter Sterken has developed and published several nonprofit methods for the risk assessment of trees and palms. Originally from Belgium, he is now based in Spain, working as an independent researcher and

tree consultant. He does not represent any commercial method, product or device. For more information: www. peterarboriculture.wordpress.com. 


\section{Acknowledgement}

The author would like to express his deepest gratitude towards Wim Peeters from Belgium for reviewing this paper and for his outstanding expertise.

\section{References}

Baker, C.J., and H.J. Bell (1992), 'The aerodynamics of urban trees', Journal of Wind Engineering and Industrial Aerodynamics 41-44: 2655-66.

Bond, J. (2006), 'Foundations of tree risk analysis: Use of the $t / R$ ratio to evaluate trunk failure potential', Arborist News, International Society of Arboriculture, December issue: 31-4.

Claire, B., M. Fournier, M. Franc, O. Prevost, J. Beauchene and S. Bardet (2003),

'Biomechanics of buttressed trees', American Journal of Botany 90(9): 1349-56.

Detter A., E. Brudi and F. Bischoff (2005), Statics Integrated Methods: Results from Pulling Tests in Past Decades, Congress Barcelona, ISA Spain (Asociación Española de Arboricultura).

Ennos, R., and A. van Casteren (2009),

'Transverse stresses and modes of failure in tree branches and other beams', Proceedings of the Royal Society B. 277: 1253-8.

Gruber, F. (2008), 'Untenable failure criteria for trees: I. The residual wall thickness rule', Arboricultural Journal 31:1, 5-18. DOI: 10.1080/03071375.2008.9747514.

Huang Y.S., F.L. Hsu, Lee C.M. and J.Y. Juang (2017), 'Failure mechanism of hollow tree trunks due to cross-sectional flattening.' R. Soc. open sci. 4: 160972. http://dx.doi.org/10.1098/rsos.160972

James, K. R. (2010), 'A dynamic structural analysis of trees subject to wind loading', PhD thesis, Melbourne School of Land and Environments, The University of Melbourne.

James, K.R., G.A. Dahle, J. Grabosky, B. Kane and A. Detter (2014), 'Tree biomechanics literature review: dynamics', Arboriculture \& Urban Forestry 40(1): 1-15.

Mattheck C., K. Betghe and O. Kraft (2008), 'Are the failure criteria of SIA (Statics Integrated Assessment) and pulling tests wrong?', Arboricultural Journal 31: 181-8.

Niklas, K.J, and H. Spatz (2010), 'Worldwide correlations of mechanical properties and green wood density', American Journal of Botany 97(10): 1587-94.
Peltola, H.M. (2006), 'Mechanical stability of trees under static loads', American Journal of Botany 93(10): 1501-11.

Spatz, H.C., and J. Pfisterer (2013), 'Mechanical properties of green wood and their relevance for tree risk assessment', Arboriculture \& Urban Forestry 39(5): 218-25.

Sterken, P. (2005), A Guide for Treestability Analysis, second and expanded edition. ISBN: 9090193774

Sterken, P. (2006), 'Prognosis of the development of decay and the fracture-safety of hollow trees', Arboricultural Journal 29:4: 245-67.

Wagener, W.W. (1963), Judging Hazard from Native Trees in California Recreational Areas: A Guide for Professional Foresters, USFS Research Paper PSW-PI. 29pp.

Wessolly, L., and M. Erb (1998), Handbuch der Baumstatik und Baumkontrolle,

PatzerVerlag, Berlin, Germany.

Wessolly L., and M. Erb (2016), Manual of Tree Statics and Tree Inspection (English edition), Patzer Verlag. Berlin-Hanover, Germany. ISBN 978-3-87617-143-2
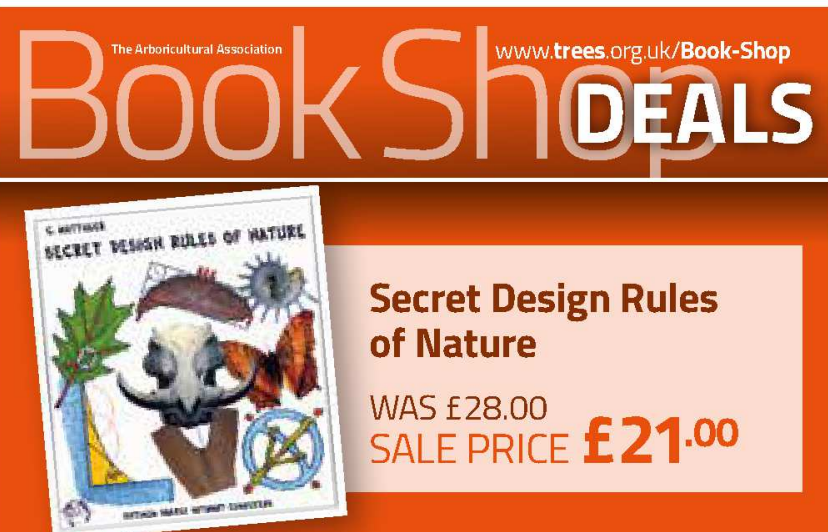

Secret Design Rules

of Nature

WAS $\mathrm{f} 28.00$

SALE PRICE £21.00

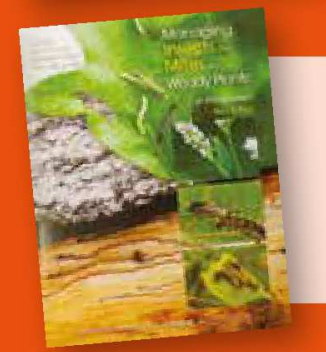

Managing Insects and Mites on Woody Plants

WAS $\mathrm{A} 47.00$

SALE PRICE $\mathbf{1 4 . 5 0}$

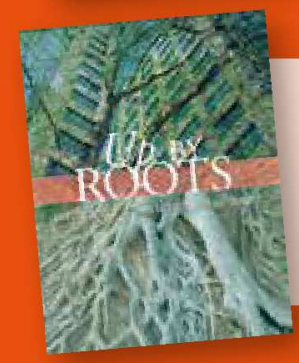

Up by Roots

WAS 185.00 SALE PRICE $\mathbf{E 7 4 , 0 0}$

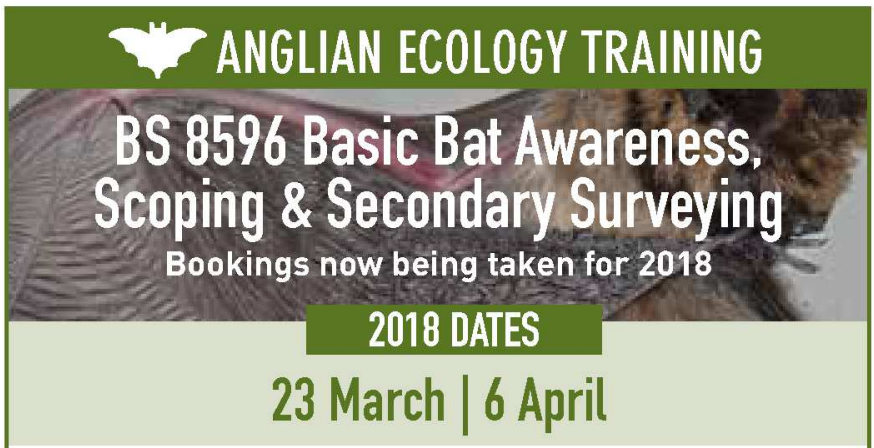

An assessed, certificated one-day course - supported by the Arboricultural Association - involving classroom and practical sessions. Near Eye in Suffolk

Successful participants will gain the following skills. as advocated in BS 8596 :

completing non-specialist initial scoping of trees, woods \& habitat t? undertaking secondary non-specialist PRF surveys in trees and woods

Anglian Ecology has been running its popular, demanding courses for over five years - providing training to staff from [among others] the National Trust, tree and woodland charities, architects, countryside rangers,

the London Tree Officers Association, the Forestry Commission,

local authorities, commercial contracting arborists and consultants.

Course fees are $€ 175$ per delegate per day including lunch and all refreshments.

\section{Contact details:}

Please don't hesitate to email or ring if you have any queries. Sue Morgan David Mitchell Email: suemorgan06rahotmail.com_ Email: dave.treelavirgin.net Mobile: 07753406866 